\title{
UM ESTUDO HISTÓRICO SOBRE O PROCESSO DE IMPLANTAÇÃO DO COLÉGIO TIRADENTES DA POLÍCIA MILITAR DE UBERABA-MG (1964-1968)
}

DOI: http://dx.doi.org/10.1590/2236-3459/59894

\author{
Anelise Martinelli Borges Oliveira \\ Universidade Estadual Paulista, Brasil. \\ Raquel Lazzari Leite Barbosa \\ Universidade Estadual Paulista, Brasil.
}

$\cos 80$

\begin{abstract}
Resumo
O estudo objetiva compreender o processo de implantação do Colégio Tiradentes da Polícia Militar de Uberaba (CTPM-Uberaba), atentando-se para as conjunturas militares, políticas e religiosas das quais o Brasil era palco e, mais especificamente, o Estado de Minas Gerais e a cidade de Uberaba. O recorte temporal compreendeu o período de 1964 a 1968, que corresponde à abertura do colégio, em salas emprestadas do Grupo Escolar Uberaba, e à inauguração do prédio novo. Para tanto, foram utilizadas fontes documentais da época, como legislação, jornal, fotografias e documentos militares. Os resultados mostraram uma preocupação das autoridades civis-militares em difundir os valores militares para além dos quartéis, num período em que o autoritarismo militar vinha ganhando força no Brasil.

Palavras-chave: Colégio Tiradentes da Polícia Militar-Uberaba (CTPM-Uberaba), ditadura militar, militarismo.
\end{abstract}

\section{A HISTORICAL STUDY OF THE DEPLOYMENT PROCESS OF THE COLÉGIO TIRADENTES DA POLÍCIA MILITAR DE UBERABA-MG (1964-1968)}

\begin{abstract}
The objective was to understand the deployment process the Colégio Tiradentes da Polícia Militar de Uberaba (CTPM-Uberaba), paying attention to military situations, political and religious to which Brazil was the stage and, more specifically, the state of Minas Gerais and the city of Uberaba. The time frame covers the period 1964-1968, which corresponds to the opening of the college in borrowed rooms of the School Group Uberaba, and the inauguration of the new building. To this end, will be used documentary sources of the time, such as legislation, newspaper, photographs and military documents. The results showed a concern of civil-military authorities in spreading the values beyond the military barracks, at a time when the military authoritarianism was gaining strength in Brazil.

Keywords: Colégio Tiradentes da Polícia Militar-Uberaba (CTPM-Uberaba), military dictatorship, militarism.
\end{abstract}




\section{UN ESTUDIO HISTÓRICO ACERCA DEL PROCESO DE EJECUCIÓN DEL COLÉGIO TIRADENTES DE LA POLICIA MILITAR DE UBERABA-MG (1964-1968)}

\section{Resumen}

Este estudio tuvo como objetivo comprender el proceso de implementación del Colégio Tiradentes da Polícia Militar de Uberaba (CTPM-Uberaba), prestando atención a las situaciones militares, políticas y religiosas a los que Brasil fue el escenario y, más específicamente, el estado de Minas Gerais y la ciudad de Uberaba. El marco de tiempo abarca el período 1964 a 1968, lo que corresponde a la apertura de la escuela en habitaciones prestadas del Grupo Escolar Uberaba, y la inauguración del nuevo edificio. Para ello, se utilizarán las fuentes documentales de la época, tales como la legislación, prensa, fotografías y documentos militares. Los resultados mostraron una preocupación de las autoridades civiles y militares en la difusión de los valores más allá de los cuarteles militares, en un momento en el autoritarismo militar fue ganando fuerza en Brasil.

Palabras clave: Colégio Tiradentes da Polícia Militar-Uberaba (CTPM-Uberaba), dictadura militar, militarismo.

\section{UNE ÉTUDE HISTORIQUE SUR ENVIRON LE PROCESSUS DE IMPLANTATION DU COLÉGIO TIRADENTES DA POLÍCIA MILITAR DE UBERABA-MG (1964-1968)}

\section{Résumé}

L'objectif visait comprendre le processus de déploiement du Colégio Tiradentes da Polícia Militar de Uberaba (CTPM-Uberaba), prêtant attention aux situations militaires, de politique et religieuse qui le Brésil a été la scène et, plus spécifiquement, de l'état de Minas Gerais et de la ville de Uberaba. Le laps de temps de 1964 à 1968 couvre la période, ce qui correspond à l'ouverture du école dans les chambres empruntés du Grupo Escolar Uberaba, et l'inauguration du nouveau bâtiment. A cet effet, seront utilisés les sources de l'époque documentaires, comme la législation, les journaux, les photographies et les documents militaires. Les résultats ont montrent une préoccupation des autorités civiles et militaires dans la diffusion des valeurs au-delà des casernes militaires, pendant une période où l'autoritarisme militaire a été gagne en force au Brésil.

Mots-clés: Colégio Tiradentes da Polícia Militar-Uberaba (CTPM-Uberaba), dictature militaire, militarisme. 


\section{Introdução}

$\mathrm{N}$

os últimos trinta anos, pesquisas acadêmico-científicas sobre a história das instituições escolares vêm constituindo uma área de investigação na esfera da historiografia da educação no Brasil (para citar alguns: GATTI JUNIOR, 2002; SANFELICE, 2007; VEIGA, 2002). O processo histórico-educacional pelo qual a instituição escolar se organizou - e ainda se organiza - permite constatar que a concepção de escola está associada às esferas histórica, política, econômica e social de cada época, uma vez que tal concepção relaciona-se à cultura, valores e crenças de determinada sociedade.

A pesquisa sobre as instituições escolares aparece como uma abordagem teórica e metodológica que, não obstante trate de espaços e tempos específicos, insere-se numa perspectiva mais ampla, qual seja, a realidade educacional vivenciada no país. Esse estudo "[...] confere relevância epistemológica e temática ao exame das singularidades sociais em detrimento das precipitadas análises de conjunto, que, sobretudo na área educacional, faziam-se presentes [até então]" (GATTI JÚNIOR, 2002, p. 4).

Devido a seu caráter histórico, o estudo das instituições escolares exige a utilização de uma série de fontes documentais, como, por exemplo, atas, livros de matrícula, relatórios, programas de disciplina, fotografias, legislação, jornais da época e entrevistas. Conforme mostra Miguel (2007, p. 31), os arquivos encontrados podem proporcionar uma nova forma de se pensar/fazer pesquisa, pois "[...] a descoberta de novos registros que contenham informações sobre determinada instituição, trazem sempre a expectativa da descoberta, a possibilidade de novos direcionamentos ao trabalho, apontando para novas interpretações". Para além do registro sistemático baseado nas evidências do passado, ou mesmo do presente, a pesquisa sobre a instituição escolar pretende:

[...] ir em busca de suas origens, do seu desenvolvimento no tempo, das alterações arquitetônicas pelas quais passou, e que não são gratuitas; é ir em busca da identidade dos sujeitos (professores, gestores, alunos, técnicos e outros) que a habitaram, das práticas pedagógicas que ali se realizaram, do mobiliário escolar que se transformou e de muitas outras coisas. (SANFELICE, 2006, p. 24)

A compreensão da identidade e singularidade da instituição escolar só estará imbuída de sentido se vier acompanhada da compreensão do contexto em que ela se insere, uma vez que a mesma não existe de forma isolada.

No caso do objeto de estudo deste artigo - o Colégio Tiradentes da Polícia Militar de Uberaba-MG (CTPM-Uberaba) - sua implantação está intimamente relacionada às questões política, militar e religiosa de que o Brasil era palco e, mais especificamente, Minas Gerais e Uberaba. Esse colégio foi criado por iniciativa do Comandante Geral da Polícia Militar de Minas Gerais em 1964, ano em que tem início o período ditatorial militar no país.

O CTPM-Uberaba é destinado preferencialmente a dependentes de policiais e bombeiros militares e é mantido pela Polícia Militar de Minas Gerais (PMMG) com subsídios do Estado de Minas Gerais. Atualmente integra uma rede de vinte e duas instituições de ensino presentes no Estado.

Esta pesquisa aborda o processo da criação e da conquista do prédio próprio do 
CTPM-Uberaba, atentando para as conjunturas militar, política e religiosa que interferiram diretamente nesse processo. Antes, porém, são feitas considerações acerca das relações entre o militarismo no país e a implantação de estabelecimentos de ensino secundários mantidos pela PMMG.

A participação direta das Forças Armadas (Exército, Marinha e Aeronáutica) e das Forças Auxiliares do Exército (Policiais e Corpo de Bombeiros Militares), em momentos de crise institucional, evidencia como as corporações militares estiveram presentes no cenário político brasileiro. A indissociabilidade entre as esferas política e militar se faz presente uma vez que aquelas corporações detêm os meios de coerção legal, com vistas "[...] à execução da política de segurança nacional [...]", inserindo-se no aparelho burocrático do Estado, "[...] sob a autoridade suprema do Presidente da República [...]" (BRASIL, 1999).

Não por acaso, as Forças Armadas e Auxiliares participaram do Golpe Republicano (1889), da destituição da República Oligárquica (1930), da implantação do Estado Novo (1937), da deposição de Getúlio Vargas (1945) e do Período Populista (1945-1964). Até 1964 a intervenção das corporações militares nas decisões governamentais teve como finalidade o restabelecimento da "ordem" política e a transferência do poder para os civis. Naquele ano, porém, os militares não apenas intercederam em favor da "segurança nacional" , como também estabeleceram a ditadura militar, permanecendo no poder até 1985.

Nos períodos em que as corporações militares têm um papel de destaque no Estado, a educação passa a ser compreendida como uma ferramenta de controle social na medida em que desempenha o papel de ligar a sociedade aos ideais defendidos pelas corporações militares:

A associação entre educação e segurança nacional tem sua origem no Brasil em momentos de política autoritária, quando a educação é enaltecida como instrumento eficaz de controle. Não seria incorreto dizer que o discurso de que a educação, bem planejada e disseminada, garante a ordem e a disciplina está na verdade invertido. Ao contrário, a necessidade imperativa da ordem e da disciplina define o que será e a que servirá a educação. (BONEMY, 1999, p. 141)

O primeiro estabelecimento de ensino secundário de modelo militar, o Colégio Militar do Rio de Janeiro (CMRJ), foi implantado em 1889, sendo o mais antigo em atividade no país. A criação do colégio esteve relacionada às mudanças de cunho reformista no processo de profissionalização do Exército, que contava com a diversificação e ampliação do ensino militar e com a atribuição de prover o ensino secundário aos alunos que pretendessem seguir a carreira militar. Tais mudanças se articularam com a própria institucionalização do Exército a partir da vitória na Guerra do Paraguai (1864-1870), bem como com a emergência dos militares no cenário político brasileiro, notadamente em relação à intervenção militar na implantação do regime republicano em novembro de 1889 . Cabe observar, portanto, que a criação do CMRJ se

\footnotetext{
1 O conceito de segurança nacional teve origem na concepção estadunidense de mobilização permanente para fazer frente a qualquer ameaça que viesse a prejudicar o desenvolvimento econômico do país. No Brasil, a doutrina da segurança nacional "[...] foi traduzida em termos da urgência militar de enfrentar os problemas nacionais como um conjunto, onde os aspectos sociais e políticos seriam indissociáveis dos aspectos militares". (MARTINS FILHO, 2008, p. 108)
} 
deu em um momento peculiar por que passava o Exército. Sua implantação oportunizou a ampliação do sistema de ensino do Exército para outros Estados brasileiros, que conta atualmente com doze Colégios Militares.

As primeiras décadas do século XX foram responsáveis por uma crescente organização das corporações militares, cujas participações nas decisões políticas do país já são bastante evidentes na década de 1930, quando as Forças Armadas, juntamente com parte da elite civil, articulam dois golpes - o que colocou fim à República Oligárquica em 1930 e o que implantou a ditadura do Estado Novo em 1937. Os dois eventos tiveram como organizadores os generais Eurico Gaspar Dutra e Góis Monteiro, que, apoiados pelo presidente Getúlio Vargas, "[...] conseguiram tornar o Exército uma organização coesa, politicamente homogênea e socialmente permeável às classes média e alta da população [...]" (MARTINS FILHO, 2008, p. 104).

Em 1949, no governo Dutra (1946-1951), verificou-se uma continuidade em se profissionalizar politicamente as corporações militares, com a criação da Escola Superior de Guerra (ESG), por parte da elite militar e de oficiais da Força Expedicionária Brasileira que atuaram na Segunda Guerra Mundial (1939-1945), os quais viam a necessidade de estreitar laços com a elite civil no combate ao comunismo propagado principalmente pela União Soviética. Enquanto instituição vinculada ao Estado-Maior das Forças Armadas, a ESG atuou na organização das corporações militares e na definição de seus princípios conjuntos, favorecendo o desenvolvimento de um pensamento militar mais unificado, pautado na "[...] superação das divisões internas, das lutas de personalidade e da atuação de grupos localizados que marcavam o campo militar até então" (MARTINS FILHO, 2008, p. 107-108). A ESG vai desempenhar um importante papel no golpe militar de 1964.

Conhecida como a "Sorbonne" militar brasileira, foi nela que se gestou o projeto que seria implantado no país após o golpe. [...] O projeto da escola, a rigor o único programa estruturado presente nas forças armadas, foi hegemônico em todo o período autoritário. (MIGUEL, 2002, p. 51)

No contexto da crescente organização conferida às corporações militares, surgiu, em 1949, o primeiro estabelecimento de ensino secundário estadual mantido por uma Polícia, em Belo Horizonte, no Estado de Minas Gerais. Por meio da promulgação da lei n. 480, de 10 de novembro, pelo governador Milton Campos, cria-se o Ginásio Tiradentes, onde se oferecia o curso ginasial, atual Ensino Fundamental II, tendo como "[...] preferência na matrícula os servidores da Polícia Militar e os seus dependentes, podendo ser admitidos outros candidatos, desde que restem vagas" (MINAS GERAIS, 1949). O Ginásio Tiradentes foi implantado em salas cedidas pelo então Departamento de Instrução da PMMG, atualmente denominado de Academia da PMMG, local que ainda é responsável pela formação e treinamento dos oficiais militares. Em 1951, o ginásio foi denominado de Colégio Tiradentes da Polícia Militar (CTPM).

A escolha da denominação do colégio não foi aleatória. Em 1946, o alferes Tiradentes foi proclamado Patrono Nacional das Polícias Militares e como Dia das Polícias Civis e Militares ficou instituído 21 de abril, data de sua execução. Tais escolhas sugerem a importância conferida à figura de Tiradentes enquanto "[...] indômito protomártir da Independência, como o soldado da Lei e da Ordem" (BRASIL, 1946), no sentido de se construir um herói que pudesse representar os valores militares e nacionais. 
A simbologia conferida a Tiradentes se fez ainda maior em 1965, quando o marechal Castelo Branco, primeiro presidente militar da ditadura brasileira, proclama-o Patrono Cívico da Nação Brasileira. Assim, a escolha do nome do colégio deixou clara a preocupação com a difusão, para além das esferas militares, da imagem do patrono das polícias como herói nacional, aliada à concepção de ordem e segurança nacional. $O$ fato de Tiradentes ser proveniente do Estado de Minas Gerais também colaborou para a idealização de sua imagem, não apenas perante a corporação militar, mas também perante a sociedade mineira, atentando-se para a escola enquanto importante instituição propagadora desse ideal.

É importante ressaltar que a lógica político-militar de criação do CTPM-Belo Horizonte oportunizou a expansão de outros colégios militares no interior de Minas Gerais, a partir de 1963, em decorrência dos desdobramentos do movimento armado de 1964, que instaurou a ditadura militar no Brasil.

Para Gouvea (2009, p. 109), o levante foi consequência:

[...] de articulações e manobras entre setores da sociedade civil e as forças armadas. Os interesses em jogo, afinal, relacionavam-se de forma direta às elites nacionais, em especial ao empresariado: a autodenominada "classe produtora" associada ao capital internacional ou não. Sem o apoio desses setores - que além de promoverem violentas campanhas contra o presidente e, mais especificamente, contra todos os grupos políticos identificados com as "esquerdas" - não haveria sustentação política, econômica, ideológica e técnica ao regime militarizado que ocupou o poder após o golpe.

Com o objetivo de colocar fim ao "perigo vermelho" de esquerdização do governo Goulart (1961-1964), à "ameaça" que ele representava para a sociedade brasileira, segundo os discursos da elite da época, bem como à crise econômica que vinha se estendendo ao longo de seu mandato, parte da classe média, imprensa, proprietários rurais, empresariado nacional e internacional, parte da Igreja Católica, além dos governadores de Estados economicamente ricos - como Magalhães Pinto, do Estado de Minas Gerais, Ademar de Barros, de São Paulo e Carlos Lacerda, da Guanabara estimularam o golpe das Forças Armadas na vida política do país. O intervencionismo era justificado para se restabelecer a ordem e a disciplina, em nome da preservação da segurança nacional.

Nesse contexto, Minas Gerais, sob o governo de Magalhães Pinto (1961-1966), teve um papel importante na conspiração, ao enviar as tropas do Exército e da Polícia Militar para o Rio de Janeiro e acelerar a deposição de João Goulart.

$\mathrm{Na}$ cidade de Uberaba, grande parte dos meios de comunicação apoiaram o golpe que instituiu a ditadura militar. O principal jornal de Uberaba e da região do Triângulo Mineiro na época, o Lavoura e Comércio, foi abertamente favorável ao movimento armado. De tendência conservadora desde sua criação, em 1899, o Lavoura e Comércio noticiava acontecimentos segundo uma concepção elitista, representada, na cidade mineira, pelos criadores de gado zebu e pelos grandes comerciantes. Seu diretor, Quintiliano Jardim, era pessoa próxima do governador Magalhães Pinto.

O Lavoura e Comércio assim noticiou o golpe:

A atitude assumida pelo governador Magalhães Pinto, liderando o movimento de resistência democrática, mobilizando todas as forças vivas da Nação para a 
cruzada da libertação do Brasil daqueles que pretendem implantar a baderna, foi recebida com entusiasmo por todos os brasileiros cristãos e democratas. (LAVOURA E COMÉRCIO, 02/03/1964)

A citação acima permitiu compreender claramente a posição do jornal em relação à intervenção de Magalhães Pinto no levante armado. A fala trouxe o governador como um líder nacional, capaz de mobilizar todo o país no combate ao comunismo. O levante armado foi denominado pelo jornal "movimento de resistência democrática", ou seja, é concebido mais como uma mobilização do povo, que resistiu, de forma pacífica, à ameaça comunista, do que um golpe repressivo e autoritário, por parte dos militares e de alguns segmentos sociais, alcançado por meio da força - o que de fato aconteceu. Assim, percebe-se uma incongruência na passagem, uma vez que nomeia de democrático um golpe que se caracterizou por práticas antidemocráticas de violação à liberdade, as quais se estenderiam durante todo o período ditatorial.

Mais adiante, ao afirmar que Magalhães Pinto mobilizou "todas as forças vivas da Nação para a cruzada da libertação", a citação apontou a ação do governador como uma ação libertadora. Segundo o jornal, os brasileiros "cristãos e democratas" deveriam libertar o país da ameaça comunista e salvar a pátria da desordem. Para isso, precisavam se unir na luta contra os indivíduos que ameaçassem a soberania nacional.

Como as tropas do Exército em Minas Gerais eram consideradas incipientes, com "[...] limitações resultantes do irrisório tempo de serviço e do sistema de ampla incorporação [...]" (STARLING, 1985, p. 118), foram integradas ao levante as tropas da Polícia Militar, que, além de possuírem tradição em confrontos armados, vinham sendo equipadas e instruídas desde 1962 pelo Comandante Geral José Geraldo de Oliveira, um dos principais articuladores do golpe no Estado. Não por acaso, foi durante o comando de Oliveira frente à PMMG (1962-1966) que ocorreu a maior implantação de CTPM em um menor período de tempo, incluindo o de Uberaba, objeto deste estudo.

Até 1963, o único CTPM existente estava ligado ao 1ํㅡ Batalhão da PMMG, o batalhão mais antigo e importante de Minas Gerais, localizado em Belo Horizonte. A política instaurada pelo Comandante Geral Oliveira se caracterizou pela abertura de CTPM em cidades interioranas onde se localizavam as sedes dos batalhões da PMMG, a fim de se atender aos dependentes de policiais e bombeiros militares. Os colégios instaurados nas cidades que continham esses batalhões eram denominados "anexos", uma vez que se constituíam de unidades adjacentes ao CTPM da capital.

O Quadro 1 mostra o local bem como o ano de abertura dos anexos do CTPM. 
Quadro 1 - Local e ano em que foram abertos os anexos do CTPM de Belo Horizonte durante o Comando Geral do Coronel Oliveira na PMMG.

\begin{tabular}{|c|c|c|}
\hline Cidade & Batalhão da PMMG & $\begin{array}{l}\text { Ano de Abertura dos } \\
\text { Anexos do CTPM }\end{array}$ \\
\hline Juiz de Fora & $2^{\circ}$ Batalhão & 1963 \\
\hline Diamantina & 3ํBatalhão & 1963 \\
\hline Uberaba & $4^{\circ}$ Batalhão & 1964 \\
\hline Governador Valadares & 6 Batalhão & 1964 \\
\hline Bom Despacho & 7º Batalhão & 1964 \\
\hline Lavras & 8 Batalhão & 1964 \\
\hline Barbacena & 9 Batalhão & 1964 \\
\hline Montes Claros & 10 Batalhão & 1964 \\
\hline Manhuaçu & $11^{\circ}$ Batalhão & 1965 \\
\hline Passos & 12ํㅡ Batalhão & 1966 \\
\hline
\end{tabular}

Fonte: Dados retirados do Boletim do Comando Geral da PMMG n. 1 (1965, p. 2).

$\mathrm{O}$ quadro anterior permitiu observar que, durante os quatro anos de mandato do Comandante Geral Oliveira na PMMG, foram abertos dez anexos do CTPM de Belo Horizonte. Considerando que o $1^{\circ}$ e 0 5o Batalhão estavam aquartelados na capital do Estado e que até 1966 existiam em Minas Gerais 12 batalhões, pode-se inferir que as cidades sede de todos os batalhões do interior receberam um anexo do CTPM e que a abertura desses anexos estava diretamente relacionada ao tempo de existência dos batalhões.

As datas de abertura dos anexos, verificadas no Quadro 1, permitiram entender que o Comandante Geral Oliveira não teve empecilho que pudesse dificultar a institucionalização dos mesmos. Isso evidencia o prestígio que tinha junto ao governador Magalhães Pinto, pois, como esses estabelecimentos de ensino eram mantidos pela PMMG, uma corporação estadual, precisavam da aprovação do governo do Estado para serem instituídos.

O Quadro 1 mostrou que os anexos foram criados em um curto espaço de tempo. Os anos de fundação - 1963, 1964 e 1965 - revelaram a preocupação da PMMG e, mais especificamente, do governador Magalhães Pinto e do Comandante Geral Oliveira, em se difundir os valores militares para além dos quartéis, num período em que o autoritarismo militar vinha ganhando força no Brasil. Pode-se inferir que para esses dirigentes a escola tinha por função preparar o aluno de acordo com os valores que se quer transmitir. Desse modo, o CTPM da Capital e os anexos passaram a ser concebidos como instituições formadoras de crianças e jovens capazes de se apropriarem e reproduzirem os valores militares, valores esses pautados na crença do catolicismo e na exaltação da pátria, da família e das corporações militares por meio de uma formação considerada moral e ética.

Assim como o colégio da Capital, todos os anexos foram em um primeiro momento denominados "Ginásio Tiradentes" e funcionavam como estabelecimentos de ensino secundário que priorizavam dependentes de policiais militares. Em decorrência da 
lei estadual n. 4941, de 12 de setembro de 1968, que modificou a denominação de Ginásio para Colégio, nos estabelecimentos de ensino básico que ministravam cursos do segundo ciclo (atual ensino médio), os anexos, bem como o colégio da capital, passaram a se chamar Colégio Estadual Tiradentes da Polícia Militar. Apesar de essa rede de colégios ser uma instância vinculada ao Estado, foi retirado de seu nome a palavra Estadual e acrescentado Minas Gerais. Atualmente, a rede é denominada Colégio Tiradentes da Polícia Militar de Minas Gerais - sigla: Colégio Tiradentes da PMMG - e a diferenciação na nomenclatura entre os colégios da rede se dá pelo nome da cidade/unidade em que o colégio está inserido (Colégio Tiradentes da PMMG-Uberaba; Colégio Tiradentes da PMMG-Passos etc.). Além daquela nomenclatura, também foi verificada a utilização de outra denominação nos documentos oficiais dos colégios da rede. Em editais de concurso público, ou mesmo em documentos internos como o Regimento Escolar, aparece o nome Colégio Tiradentes da Polícia Militar (CTPM), que vem acompanhado da cidade/unidade do mesmo: CTPM-Uberaba; CTPM-Passos etc. O presente trabalho adotou essa última denominação.

Além de Belo Horizonte e das cidades já citadas no Quadro 1, foram criados CTPM em outras cidades que passaram posteriormente a ser sedes de batalhões. Pela ordem cronológica de abertura, são elas: Patos de Minas (1977), Ipatinga (1981), Teófilo Otoni (1999), Betim (2003), Vespasiano (2005), Uberlândia (2015) e Pouso Alegre (2015). Belo Horizonte possui cinco unidades, sendo a única cidade do Estado a ter mais de uma unidade; são elas: Argentino Madeira, Gameleira, Minas Caixa, Nossa Senhora das Vitórias e Contagem. Assim, os CTPM totalizam uma rede de vinte e duas unidades pelo Estado de Minas Gerais. A maioria dessas unidades atende o Ensino Fundamental I e II e - Ensino Médio. Com a crescente procura de vagas para dependentes de policiais e bombeiros militares, bem como de membros da sociedade civil, as unidades têm aumentado seus alunos, que atualmente são mais de dezoito mil, o maior número registrado até hoje ${ }^{2}$. Algumas unidades expandiram 0 atendimento do ensino para 0 Ensino Fundamental I, como é o caso do CTPM-Uberaba, objeto do presente estudo. Todas as unidades existentes foram instituídas pelo Comandante Geral da PMMG juntamente com o Comandante do Batalhão da cidade onde o colégio seria aberto.

Como qualquer escola pública estadual, os CTPM prestam contas à Secretaria Estadual de Educação de Minas Gerais. No entanto, possuem especificidades administrativas e pedagógicas que os diferenciam dos demais estabelecimentos de ensino públicos. Os CTPM são mantidos pelo Estado de Minas Gerais através da PMMG, mas também recebem recursos diretos da Secretaria Estadual de Educação. Todos os recursos, mesmo os oriundos da PMMG, passam primeiramente pela Superintendência Regional de Ensino.

A rede de colégios é subordinada ao Comandante Geral da corporação e possui um sistema próprio de ensino, o Sistema de Educação Escolar da PMMG. Está vinculada e subordinada à Diretoria de Educação Escolar e Assistência Social (Deeas), órgão que corresponde "[...] à Unidade de Direção Intermediária responsável, perante o Comandante-Geral, pelo planejamento, coordenação, controle e supervisão técnica das

2 O número foi obtido por meio de consultas a editais e de informações fornecidas por responsáveis das unidades nos dias 21 e 22 de setembro de 2015. 
atividades especificas de educação escolar e de assistência social da Polícia Militar de Minas Gerais [...]" (PMMG. Resolução n. 4.209, de 16 de abril de 2012, p. 2). O DEEAS localiza-se em Belo Horizonte, no CTPM-Gameleira, e possui a seguinte estrutura: Diretoria; Subdiretoria; Seções: Análise Jurídica, Normas e Planejamento de Assistência Social, Normas e Planejamento Pedagógico, Organização e Atendimento Escolar, Habitacional e Administrativa. Atualmente existe uma proposta de institucionalização do DEEAS como um apêndice da Secretaria Estadual de Educação, o que lhe concederia a mesma autonomia da Superintendência de Ensino na tomada de decisões referente aos CTPM. É interessante observar que tal institucionalização viria proporcionar ampla independência em relação ao governo estadual, fato que colaboraria, consequentemente, para o fortalecimento da própria PMMG diante do Estado e da sociedade, uma vez que teria liberdade de decisões.

Todas as unidades possuem o mesmo Regimento Escolar, conjunto de normas elaborado pela PMMG que define sua organização e estrutura. Não obstante os CTPM possuam características homogêneas em relação ao vínculo e à subordinação, verificamse peculiaridades que são inerentes a cada colégio. Assim, cada unidade possui basicamente 0 seguinte corpo administrativo/pedagógico: direção administrativa (Comandante do Batalhão onde se encontra a unidade), direção pedagógica e vicedireção pedagógica (professores do colégio eleitos), secretaria de ensino (oficial da PMMG), monitoria (oficiais da PMMG), supervisão pedagógica, orientação pedagógica e corpo docente concursado por um edital específico.

Em decorrência das várias funções militares conferidas ao Comandante do Batalhão, as quais o impossibilitam, muitas vezes, de participar do cotidiano do colégio, a PMMG criou, em 2011, o cargo de coordenador administrativo, um intermediário entre o diretor administrativo e o colégio. Esse cargo é ocupado por um oficial da corporação nomeado pelo Comandante do Batalhão com as mesmas atribuições do diretor administrativo. Apesar de oficialmente o diretor administrativo ser a pessoa que dirige 0 CTPM, na prática, esse papel é feito diariamente pelo coordenador administrativo. Assim, são atribuídas a ele funções administrativas como manutenção predial, finanças, contratação de pessoal, designação, demissão de pessoas etc. No dia a dia do colégio, é a autoridade máxima, e todos os alunos e funcionários, inclusive o diretor pedagógico, devem prestar contas a ele.

$\mathrm{Na}$ prática, o coordenador administrativo também interfere nas ações pedagógicas da escola, pois possui autonomia para modificar o que julgar necessário. Segundo relato de um coordenador administrativo da rede, a interferência pedagógica ocorre de várias formas. Assim, com relação ao processo ensino-aprendizagem, pode intervir na metodologia aplicada pelo professor em sala de aula, instituindo condutas a serem adotadas por esse, com vistas, por exemplo, ao aumento do resultado das avaliações dos alunos e ao controle da disciplina, além de fiscalizar o comportamento dos alunos na sala de aula por meio do visor das janelas. Cabe destacar, portanto, o coordenador administrativo enquanto indivíduo que possui autoridade para coibir condutas consideradas reprováveis e primar pela normatização de comportamentos que são considerados dignos de serem reproduzidos pelos sujeitos que compõem as unidades dos CTPM.

Em relação ao corpo discente, as vagas são destinadas, em ordem de prioridade, 
a: "[...] dependentes de militares da PMMG, dependentes de servidores civis e demais candidatos que preencham os requisitos de seleção das unidades" (PMMG. Resolução n. 4.209, de 16 de abril de 2012, p. 20). Os pais e/ou responsáveis pelo aluno devem assinar um termo de compromisso no início do ano letivo concordando com as exigências do colégio em relação a vários assuntos, dentre eles custear o uniforme, que é obrigatório e se assemelha ao vestuário militar, prezar pela 'disciplina' e pela 'conduta" do filho'" (PMMG. Edital n. 01, 2014, p. 11). Como consta em documento oficial, os CTPM "[...] mantém regime disciplinar compatível com o preparo para o ingresso à carreira militar e para as instituições civis de ensino superior" (PMMG. Resolução n. 4.209, de 16 de abril de 2012, p. 20). Tal afirmação evidencia a preocupação em se reproduzir e se adotar, nos colégios, os valores preconizados pela PMMG.

\section{Colégio Tiradentes da Polícia Militar de Uberaba-MG: processo histórico de implantação}

Conforme visto anteriormente, os CTPM são instituídos pelo Comandante Geral da PMMG, juntamente com o Comandante do Batalhão da cidade onde serão criados. No que tange ao CTPM-Uberaba, foi instituído em 1964 pelo Comandante Geral Oliveira e pelo Comandante do $4^{\circ}$ Batalhão, o Tenente Coronel Altivo de Assis Fonseca. $O$ Comandante Geral autorizou sua implantação nos seguintes termos:

Determino a criação do Anexo IV do Colégio Tiradentes da Polícia Militar junto ao $4^{\circ}$ B. I. [Batalhão de Infantaria], sediado em Uberaba. O referido anexo deverá ter a sua direção e funcionamento regidos pelos regulamentos do Colégio Tiradentes, ao qual ficará diretamente subordinado. (PMMG. Boletim do Comando Geral n. 200, de 26 de outubro de 1964, p. 2176)

O anexo foi denominado Ginásio Tiradentes em abril de 1964 e, no mesmo mês, obteve autorização do Ministério da Educação e Cultura para funcionamento:

O Inspector Seccional do Ensino Secundário de Uberaba [...] resolve: conceder ao Ginásio "Tiradentes", situado na cidade de Uberaba, Minas Gerais, autorização para funcionar condicionalmente, "ad referendum" do Senhor Diretor do Ensino Secundário pelo prazo de quatro anos. (MINISTÉRIO DA EDUCAÇÃO E DA CULTURA, 16/04/1964)

A institucionalização do colégio foi muito valorizada pela imprensa local e, especificamente, pelo jornal Lavoura e Comércio, o qual destacou que sua abertura veio confirmar a tradição da cidade em se ter instituições de ensino de qualidade: "Uberaba passa a contar com mais um estabelecimento de ensino secundário, firmando-se como das mais adiantadas cidades do interior, no setor educacional" (LAVOURA E COMÉRCIO, 12/02/1964).

Devido à inexistência de instalações próximas ao 4ํㅡㄹ Batalhão da Polícia Militar, o Ginásio Tiradentes passou a funcionar, em fevereiro de 1964, nas dependências do Grupo Escolar Uberaba durante o período noturno. 


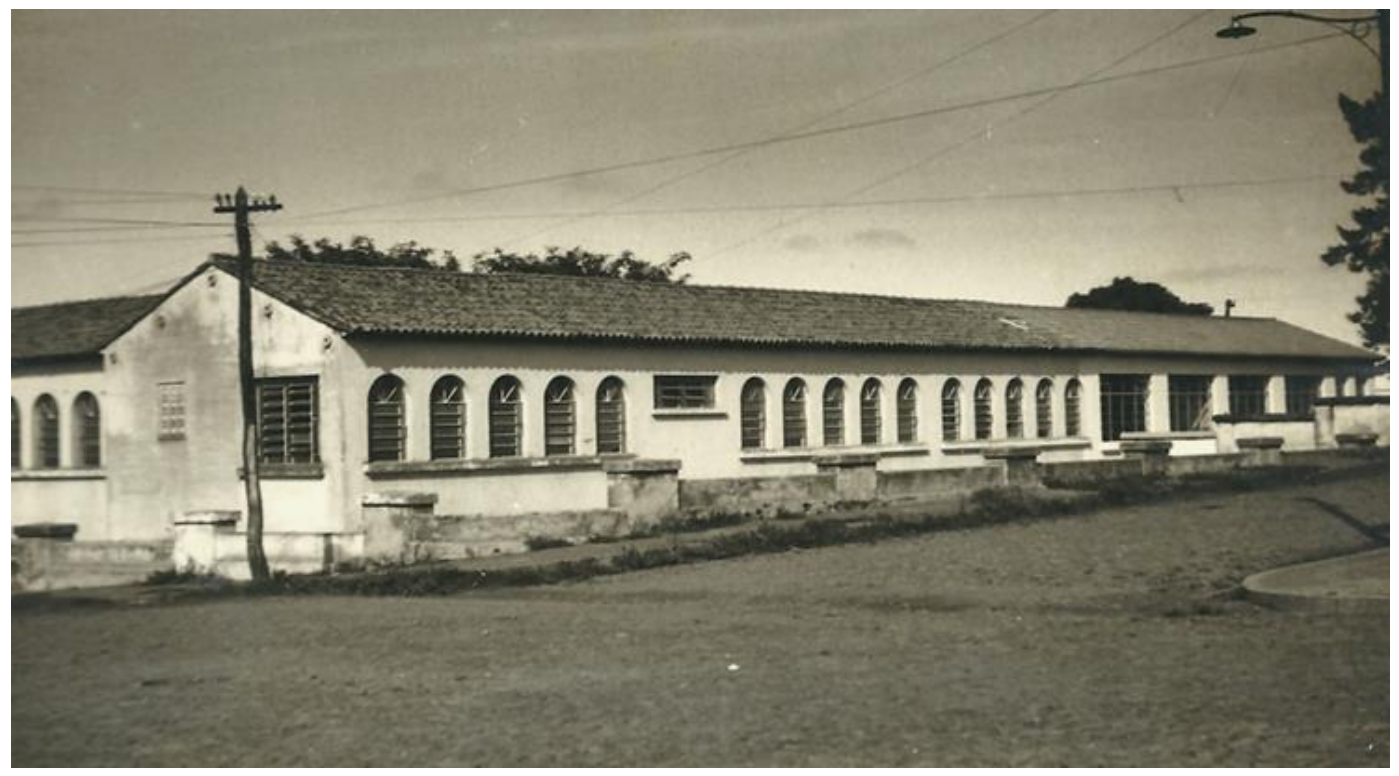

Figura 1 - Fachada do Grupo Escolar Uberaba no início da década de 1960, local onde o CTPM-Uberaba funcionou de 1964 a 1967.

Fonte: Arquivo do CTPM-Uberaba.

Os primeiros professores foram oficiais do 4ํ Batalhão da PMMG, que se revezavam entre os encargos militares e a docência. Em decorrência da falta de professores, bem como de um concurso público efetivo, o corpo docente também era integrado pelas filhas dos militares que, na época, faziam cursos de formação de professores.

Inicialmente, foram criadas salas com oitenta alunos para o curso de admissão, um curso preparatório para a realização do exame de admissão, que era feito pelos alunos que haviam concluído o curso primário e pretendiam cursar o ginásio. Após o término do curso de admissão, a primeira série do curso ginasial contava com cerca de 200 alunos.

A abertura do curso de admissão foi anunciada no Lavoura e Comércio de 12 de fevereiro de 1964: "No dia 3 próximo passado, com a presença de várias pessoas de nossa sociedade e oficiais do $4^{\circ}$ B.I [Batalhão de Infantaria], deu-se a solene abertura das aulas do Curso de Admissão do Colégio Tiradentes da Polícia Militar". Pode-se observar a intenção do jornal em enaltecer o episódio. O comparecimento da elite local no evento atestou a consonância entre essa camada social e a corporação militar.

O jornal continuou a notícia:

A aula inaugural esteve a cargo do Major Carlos de Abreu Lopes que, após ressaltar o esforço do Batalhão em conseguir a criação do Colégio com o objetivo de atender às famílias dos militares, bem como a toda sociedade uberabense, com brilhantes palavras incentivou os jovens quanto ao futuro da Pátria e da necessidade do estudo e do aprimoramento das qualidades morais e intelectuais. (LAVOURA E COMÉRCIO, 12/02/1964)

O trecho acima evidenciou a presença unilateral que os militares teriam no cotidiano do colégio, fato que já pode ser constatado na aula inaugural, ministrada por um Major. Por meio da notícia, percebe-se que o discurso do Major fora pautado na exaltação da pátria e do civismo, atentando para a ideia de que o estudo no colégio seria capaz de 
proporcionar uma formação moral embasada nos valores militares, formação essa considerada, pela elite e pela corporação militar, como a ideal de um jovem. Também ficou notória a posição do jornal em concordar e apoiar a abertura do CTPM-Uberaba.

Mais adiante, a mesma notícia pontuou:

Também fez uso da palavra o Tenente Coronel Altivo de Assis Fonseca, Comandante do Batalhão, que salientou a sua satisfação pela atividade que vem adotando a Polícia Militar no sentido de contribuir com a sua parcela para o Estado no setor educacional e desejou felicidades aos alunos que o Colégio receber. (LAVOURA E COMÉRCIO, 12/02/1964)

A citação anterior revelou, no discurso do Tenente Coronel Fonseca, Comandante do Batalhão e diretor do CTPM-Uberaba, a ideia de que a criação do colégio trouxe benefícios ao Estado de Minas Gerais. Segundo a citação, a PMMG se dispôs a participar da formação de jovens, fato que vem a ajudar o governo estatal na medida em que retira dele um encargo que demandaria tempo e custo. Desse modo, notou-se na fala do diretor o cuidado em transmitir a imagem de que a PMMG é uma instância que não apenas se preocupa com suas atribuições militares oficiais, mas também com âmbitos relacionados diretamente à sociedade, como é o caso da educação.

O CTPM-Uberaba permaneceu nas salas emprestadas do Grupo Escolar Uberaba até o ano de 1967, quando foi inaugurada sua instalação própria. Assim como a ampliação da rede de CTPM para as cidades do interior na década de 1960, a conquista do prédio próprio do CTPM-Uberaba foi marcada igualmente por questões inerentes ao momento político e militar pelo qual passava o país. Para além dessas questões, no entanto, a construção do próprio estabelecimento de ensino também esteve associada às articulações entre Estado e Igreja Católica.

A conspiração militar de março de 1964 desencadeou consequências para Uberaba. Um dia antes do golpe, o Comandante Geral Oliveira nomeara para o comando do $4^{\circ}$ Batalhão na cidade mineira o Tenente Coronel Nazareth, que já no primeiro dia de gerência cumpriu ordens vindas da capital, como o monitoramento nas rodovias do Triângulo Mineiro que davam acesso ao Estado de São Paulo.

Em Uberaba, Nazareth foi responsável por medidas de fiscalização em domicílios, estabelecimentos comerciais e educacionais que pudessem vir a ser considerados subversivos do ponto de vista dos dirigentes que estavam à frente do golpe militar. Para tanto, era investigada qualquer pessoa que fosse suspeita de ser contrária ao recente governo, devido, por exemplo, a boatos sobre simpatia pelo comunismo ou desacato à autoridade militar. Uma dessas inspeções ocorreu na FISTA (Faculdade de Filosofia, Ciências e Letras Santo Tomás de Aquino), instituição de ensino superior de cunho católico que era coordenada pelo arcebispo D. Alexandre Gonçalves do Amaral. A maior parte do corpo docente da instituição era composta por membros da Igreja, como monsenhores, padres, freiras e o próprio arcebispo, os quais ministravam disciplinas das ciências humanas e biológicas. Segundo relato de D. Alexandre, três oficiais do $4^{\circ}$ Batalhão, "[...] em nome do Governo Revolucionário de 64 [...] convocaram todos os professores e começaram a dar ordens" (AMARAL, 1994, p. 84). Na ocasião, os oficiais, sob o comando do Tenente Coronel Nazareth, tinham a intenção de fiscalizar os textos utilizados pelos professores. Tal fiscalização não foi permitida por D. Alexandre, que a considerou abusiva por violar a autoridade católica. Além desse, outros incidentes 
envolvendo Nazareth e o arcebispo vieram agravar a relação entre Igreja e Polícia Militar.

Cabe observar que o arcebispo era o principal líder católico de Uberaba e região, possuindo grande prestígio junto aos políticos e à sociedade. Após o acontecimento na FISTA, D. Alexandre foi até Belo Horizonte a fim de solicitar ao governador Magalhães Pinto a remoção de Nazareth (AMARAL, 1994). Como não era interessante para o Estado possuir desentendimentos com a Igreja, o pedido de D. Alexandre foi aceito e o Tenente Coronel Nazareth foi removido do cargo. Em seu lugar, foi nomeado o Tenente Coronel Bracarense, considerado um "católico convicto", o qual tinha como missão "reconciliar com a Igreja" (SILVEIRA, 1988, p. 176).

Assim, Bracarense passou a residir em Uberaba juntamente com sua família, assumindo em junho de 1964 o comando do $4^{\circ}$ Batalhão. Desde o início de seu mandato estabeleceu relações com os principais líderes políticos e religiosos da cidade, tornandose inclusive amigo de D. Alexandre. Enquanto "católico convicto", participou de associações religiosas, como a Sociedade Amigos do Seminário São José e a Sociedade São Vicente de Paulo, ambas de Uberaba.

Bracarense também manteve boas relações com Quintiliano Jardim, diretor do Lavoura e Comércio. Tal proximidade possibilitou à corporação militar ter uma coluna fixa no jornal a partir de 1965. Primeiramente chamada de "Notas da Polícia Militar", a coluna passou a ser denominada de "O que vai pelo $4^{\circ}$ B.l" no segundo semestre de 1966. A coluna continha notícias relacionadas à corporação segundo uma perspectiva tendenciosa, que exaltava os feitos militares na cidade e no país, tendo como escritor o militar Valter Custódio da Silva.

O prestígio do batalhão e, em especial, de Bracarense também podia ser percebido nas notícias diárias do jornal, que destacavam com frequência as ações daquele militar:

\footnotetext{
O Comandante do $4^{\circ}$ Batalhão é um nome de projeção na Polícia Militar de Minas Gerais, com um acervo de consideráveis serviços à comunidade, prestados com elevado espírito público, dignidade e competência. [...] No comando da unidade militar aqui sediada, promoveu a reforma geral das instalações do quartel, urbanização e pavimentação da parte fronteira do edifício e levantamento de um playground. O oficial distinto e digno de toda a confiança, com valiosos serviços prestados à comunidade mineira, o Ten. Cel. José Vicente Bracarense receberá expressivas e mui merecidas homenagens dos círculos militares e sociais de Uberaba. (JORNAL LAVOURA E COMÉRCIO, 21/01/1966)
}

Fica claro no trecho anterior que o comando de Bracarense junto ao $4^{\circ}$ Batalhão era concebido de forma positiva pelo jornal, devido à utilização de adjetivos valorativos para promover as atividades feitas por ele na comunidade e na sede da corporação militar. A posição do jornal mostrou-se, uma vez mais, favorável à interferência militar nas esferas sociais.

Uma das ações de Bracarense foi solicitar autorização no Comando Geral da PMMG para a construção de um prédio próprio do CTPM-Uberaba, tendo em vista que esse funcionava, desde abril de 1964, em salas emprestadas do Grupo Escolar Uberaba no período noturno. Além do colégio, foi requerida a construção da capela do $4^{\circ}$ Batalhão, que deveria ocorrer em terreno atrás do prédio do batalhão. Quando inaugurada, a capela seria coordenada pelo Capitão Capelão Luiz Gonzaga de Faria, que já era professor de 
língua portuguesa e ensino religioso no antigo prédio. Além de templo católico, a capela seria utilizada como espaço de aula de ensino religioso para os alunos do CTPMUberaba.

A solicitação das construções do colégio e da capela demonstrou uma preocupação que permeava as discussões pós-golpe civil-militar em nível nacional: a difusão dos valores militares por meio da educação e o papel da Igreja como aliada na propagação de tais valores. Ao apoiar o golpe, a Igreja entendia "[...] que era uma forma de reconduzir o país ao caminho da normalidade e da segurança e que a aliança com 0 Estado garantiria a missão evangelizadora" (SILVA, 2009, p. 243).

De acordo com o Comandante do $4^{\circ}$ Batalhão, as aulas do CTPM-Uberaba estavam ocorrendo em condições precárias, visto que, segundo ele, o prédio e o mobiliário do Grupo Escolar Uberaba estavam degradados. Em ofício de 8 de fevereiro de 1966, endereçado ao Comandante Geral em Belo Horizonte, Bracarense expôs o problema:

A situação do referido prédio é das piores, com inúmeras goteiras e com as paredes esburacadas, pintura suja e gasta, e em se tratando de carteiras, temos dificuldades com o elevado número de alunos, pois estão todas bastante usadas e com o uso tornam-se imprestáveis, não dando ao aluno a estabilidade necessária para a sua concentração às aulas, sendo elas irrecuperáveis. (PMMG. 4 Batalhão de Infantaria. Ofício n. 624, de 8 de fevereiro de 1966, p. 1)

Segundo o ofício, as más condições de uso do prédio do Grupo Escolar Uberaba interferiam diretamente no aprendizado e no rendimento dos alunos. O maior problema se dava em relação ao principal móvel de uma sala de aula, a carteira escolar, que, além de não atender a quantidade dos alunos do CTPM-Uberaba, estava deteriorada.

O local escolhido para o novo prédio do colégio foi um terreno ao lado do $4^{\circ}$ Batalhão, que também era de propriedade da corporação uberabense. A escolha do lugar sugere a preocupação dos militares em se ter o estabelecimento de ensino próximo, no sentido de acompanhar e, a partir daí, intervir de forma mais direta e rápida no dia a dia do colégio.

Assim, o $4^{\circ}$ Batalhão "[...] obteve do Exmo. Sr. Cel. Comandante Geral o pleno consentimento e o indispensável apoio [...]" e, em março, Bracarense obteve a planta do prédio (LAVOURA E COMÉRCIO, 21/03/1966). Em nota no jornal Lavoura e Comércio, a corporação militar exaltou com ufanismo o projeto da edificação: "A planta obedece o planejamento feito pelo escalão superior da corporação para os anexos do interior, isto é, um estilo moderno e com amplas instalações, devido ao grande número de alunos" (LAVOURA E COMÉRCIO, 21/03/1966). O novo prédio deveria seguir os padrões do CTPM da capital, ou seja, em formato retangular, de maneira que a largura fosse proporcionalmente maior que a profundidade, para que a construção aparentasse ser maior do que realmente era. O terreno ocuparia uma área de mil metros quadrados.

É importante observar que a autorização para a construção do prédio se deu em 1966, período no qual as corporações militares vinham adquirindo, em todo o Brasil. crescente poder de interferência no âmbito social. Nesse contexto, pode-se inferir que, para $04^{\circ}$ Batalhão, a construção do seu próprio estabelecimento de ensino vinha a favorecer a disseminação dos valores militares de forma mais "oficial" e "institucionalizada", na medida em que seria um espaço exclusivo para tal. 
Para dar início aos trabalhos, foi organizada, ainda em março, a Comissão de Construção do Colégio Tiradentes, integrada por um grupo de oficiais cujo objetivo era encarregar-se do andamento das obras. A comissão teve como supervisor geral o Comandante Bracarense. Como o Estado de Minas Gerais, por meio da PMMG da Capital, não havia liberado verba para a construção, ficou ordenado pela Comissão de Construção que cada integrante do 4ํㅡㄹ Batalhão iria contribuir com uma quantia mensal do seu salário para as obras,

[...] durante 12 meses, a partir do mês de março do corrente ano, devendo terminar, salvo motivos imprevistos, no mês de fevereiro de 1967, inclusive no vencimento de Oficiais e Praças da Unidade, a favor dos "Fundos para Construção do Anexo IV - Colégio Tiradentes", as quantias [...] que correspondem a $2 \%$ do soldo (arredondados) de cada elemento [...]. (PMMG. 4ํㅡㄹ Batalhão de Infantaria. Nota de Gabinete, de 21 de março de 1966, p. 1)

O documento anterior trazia que todas as patentes existentes na corporação uberabense, por ordem na hierarquia militar - Tenente Coronel, Major, Capitão, $1^{\circ}$ Tenente, $2^{\circ}$ Tenente, Aspirante e Subtenente, $1^{\circ}$ Sargento, $2^{\circ}$ Sargento, $3^{\circ}$ Sargento, Cabo, Soldado, Recruta -, seriam descontadas por um ano, com base no rendimento próprio mensal. Assim, por exemplo, o abatimento no pagamento do Tenente Coronel era cinco vezes o valor descontado no do Recruta. Apesar de o documento informar que os salários de todos os integrantes do $4^{\circ}$ Batalhão seriam descontados por um ano, em decorrência dos elevados custos da construção, o valor não foi suficiente e a contribuição foi prorrogada por mais um ano (PMMG. 4 Batalhão de Infantaria. Circular n. 2, de 26 de maio de 1967). Cabe lembrar que a determinação era obrigatória para todos os militares, não cabendo a eles a escolha pela contribuição mensal.

As obras iniciaram em abril de 1966 e contaram com a mão de obra de voluntários e dos próprios oficiais, principalmente de Recrutas e Soldados. A construção ocorreu de forma rápida, visto que o prédio deveria ser entregue até dezembro de 1967.

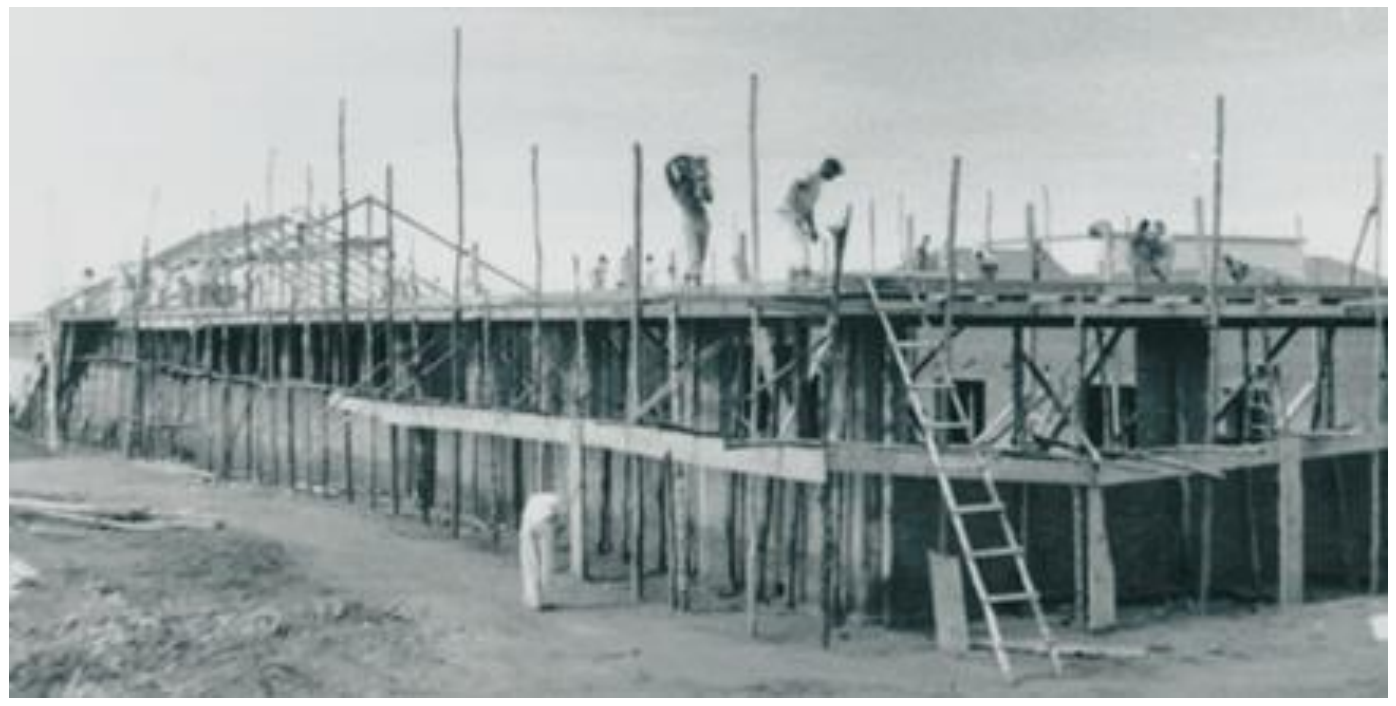

Figura 2 - CTPM-Uberaba no início da construção, em 1966.

Fonte: Arquivo do CTPM-Uberaba. 


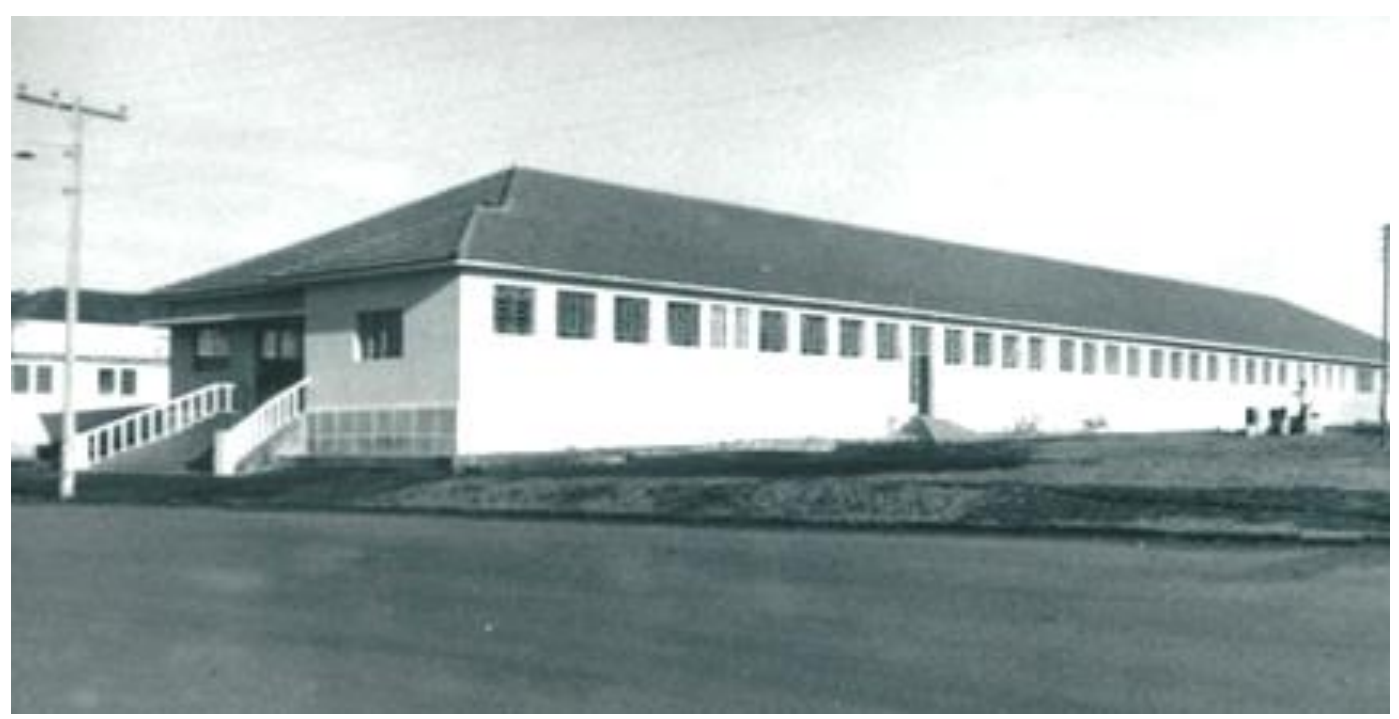

Figura 3 - CTPM-Uberaba já pronto, um ano depois, em 1967.

Fonte: Arquivo do CTPM-Uberaba.

Periodicamente, o comandante Bracarense prestava contas ao Comando Geral da PMMG do andamento das obras. Um desses documentos foi a Circular de 26 de maio de 1967, que dizia:

Ergue-se, na ala esquerda do quartel, magnífico e imponente o Seu Colégio; o Colégio de todos os que mourejam no 4 ํ Batalhão de Infantaria.

É a maior glória que pode alcançar uma coletividade - construir escolas. $04^{\circ}$ Batalhão e toda a Comunidade de Uberaba estão radiantes com essa soberba realização. Estamos semeando o saber, a fim de proporcionar aos nossos filhos uma colheita alvissareira.

Pode-se perceber, no início da fala do comandante, o tom de exaltação e enaltecimento em relação ao CTPM-Uberaba, sobretudo na utilização das palavras "magnífico" e "imponente". A todo o momento, deixou notória a ideia de que a construção foi um trabalho incessante, árduo e conjunto do $4^{\circ}$ Batalhão, de todos os militares, os quais, imbuídos de um mesmo propósito e crença, conseguiram atingir o objetivo comum. Além disso, o último parágrafo pode remeter à ideia bíblica da semeadura, segundo a qual os militares, enquanto semeadores, preparam a "terra", ou seja, o colégio planta a semente do conhecimento para que as crianças sejam os indivíduos recompensados com a ação. Evidenciou-se que no trecho destacado, a educação aparece, mais uma vez, como instrumento eficaz de disseminação dos valores militares e de controle social.

O prédio novo do CTPM-Uberaba foi inaugurado em 24 de novembro de 1967, e as aulas tiveram início em fevereiro de 1968. Seu diretor passou a ser o novo Comandante do $4^{\circ}$ Batalhão, o Tenente Coronel Osvaldo Martins, pois Bracarense foi promovido a Coronel e assumiu um cargo de alto escalão em Belo Horizonte. Apesar disso, continuou a ter, com sua família, residência fixa em Uberaba.

O colégio passou a funcionar com o curso ginasial nos períodos matutino e noturno. No período vespertino, foi implantado o curso primário, sob a denominação de Grupo Escolar Tiradentes, o qual ficou mantido pela Secretaria de Estado de Educação. Apesar de a direção desse grupo escolar ter sido determinada pela Delegacia Regional de Ensino, ele subordinava-se ao diretor do CTPM-Uberaba, o Tenente Coronel Martins. 


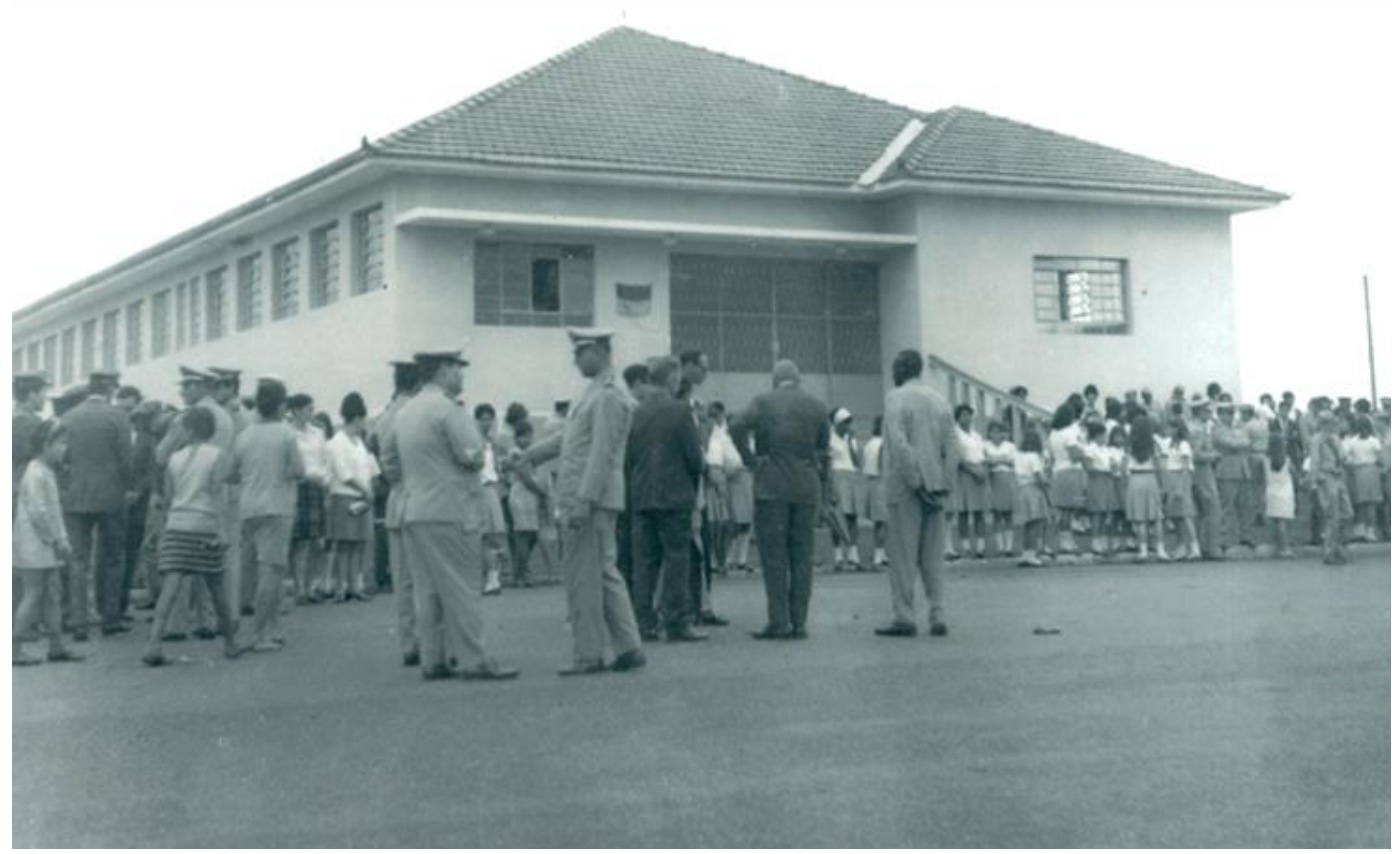

Figura 4 - Início das aulas no CTPM-Uberaba, em 1968.

Fonte: Fotografia cedida pelos familiares do Coronel Bracarense.

Em nota no jornal Lavoura e Comércio, o $4^{\circ}$ Batalhão divulgou a inauguração do CTPM-Uberaba:

\begin{abstract}
Conforme estava programado, foi solenemente inaugurado o prédio do Anexo IV do Colégio Tiradentes. No ato da inauguração foi dada a benção pelo Revmo. Pe. Luiz Gonzaga de Faria, Capelão do 4ํㅡ. B.I. Foram apresentados diversos trabalhos por alunos do Educandário em sala própria à exposição. (LAVOURA E COMÉRCIO, 30/11/1967)
\end{abstract}

Mais uma vez percebe-se a influência católica no cotidiano do colégio. Coube ao Capitão Capelão Luiz Gonzaga de Faria, coordenador da nova capela - local onde se daria o ensino religioso dos alunos a partir de 1969, quando fosse inaugurada - realizar o ritual de "proteção" ao CTPM-Uberaba, abençoando-o. Pode-se inferir que a escolha do religioso militar para fazer a cerimônia pressupõe a escolha de um indivíduo que assume uma dupla função: a de prestar assistência religiosa aos alunos, como uma autoridade católica, e a de manter a ordem, como uma autoridade militar.

\title{
Considerações finais
}

Os processos históricos de implantação e construção do CTPM-Uberaba estiveram intimamente relacionados às questões política, militar e religiosa das quais o Brasil era palco e, mais especificamente, Minas Gerais e Uberaba. Nos primeiros anos que sucederam ao golpe militar, a instituição de ensino deveria formar crianças e jovens capazes de se apropriarem e reproduzirem os valores militares.

O CTPM-Uberaba é um dos estabelecimentos de ensino mais antigos em funcionamento na cidade de Uberaba. Em que pesem as conjunturas políticas do país, como o fim do regime ditatorial militar em 1985 e o estabelecimento do regime democrático, o que se observa atualmente no cotidiano do colégio é uma continuidade em 
relação à valorização dos preceitos hierárquicos militares que foram implantados no início da ditadura militar, em 1964. Assim, valores prescritivos que visam à reprodução de uma ideologia baseada no cumprimento de ordens que estão em conformidade com as normatizações da PMMG são, ainda hoje, usualmente encontrados na rede CTPM em Minas Gerais e, especificamente, no CTPM-Uberaba. Como exemplo, pode-se citar a padronização do uniforme escolar em consonância com o vestuário militar; a utilização de cabelos aparados, por parte de alunos do sexo masculino, bem como de cabelos presos e sem tintura "exótica", por parte das alunas; a não utilização do uniforme em "lugares socialmente reprováveis"; a proibição de uso de material sem fins pedagógicos (celular, revistas, guloseimas etc.) dentro da escola; a prática de atos que venham a desrespeitar os Símbolos Nacionais; a não exposição do nome do colégio "em mensagens que atentem contra a moral"; dentre outros (PMMG, 2008).

Portanto, pode-se concluir que é importante compreender o processo de criação do CTPM-Uberaba na contemporaneidade, tendo em vista não só a crescente ampliação da rede no Estado de Minas Gerais, fato que pode ser observado, por exemplo, com a implantação de duas unidades do CTPM em 2015, como também a "militarização das escolas públicas" verificada no país a partir de 2014, uma vez que vários governos estatais brasileiros, sob o discurso de se controlar a violência e aumentar o rendimento dos alunos nos colégios, estão delegando para as Polícias Militares a gestão de escolas públicas.

\section{Referências}

AMARAL, Dom Alexandre Gonçalves. Dom Alexandre Gonçalves Amaral. In: SILVA, Décio Bragança. A história viva de Uberaba: o pensamento vivo de... Uberaba: Vitória, 1994.

BOMENY, Helena Maria Bousquet. Três decretos e um ministério: a propósito da educação no Estado novo. In: PANDOLFI, Dulce (Org.). Repensando o Estado Novo. Rio de Janeiro: FGV, 1999.

BRASIL. Decreto-Lei n. 9.208, de 29 de abril de 1946. Institui o Dia das Polícias Civis e Militares, que será comemorado a 21 de Abril. Disponível em:

$<$ http://legis.senado.gov.br/legislacao/ListaPublicacoes.action?id=104690>. Acesso em: 21 set. 2015.

. Lei Complementar n. 97, de 09 de junho de 1999. Dispõe sobre as normas gerais para a organização, o preparo e o emprego das Forças Armadas. Disponível em: <http://www.planalto.gov.br/ccivil_03/leis/LCP/Lcp97.htm>. Acesso em: 21 set. 2015.

GATTI JÚNIOR, Décio. A história das instituições educacionais: inovações paradigmáticas e temáticas. In: ARAÚJO, José Carlos Souza; GATTI JÚNIOR, Décio (Org.). Novos temas em história da educação brasileira: instituições escolares e educação na imprensa. Campinas: Autores Associados; Uberlândia: EDUFU, 2002.

GOUVEA, Viviane. Conspiração civil, golpe militar: a conspiração do IPES em palavras e imagens. Terceira Margem, Rio de Janeiro, n. 21, p. 109-128, ago./dez. 2009. Disponível em:

$<$ http://www.revistaterceiramargem.com.br/index.php/revistaterceiramargem/article/view/1 02>. Acesso em: 21 set. 2015.

JORNAL LAVOURA E COMÉRCIO. Uberaba/MG. 02 de março de 1964. Escutando e divulgando. p. 2. 
Uberaba/MG. 12 de fevereiro de 1964. Aula inaugural do curso de admissão do Colégio Tiradentes. p. 3.

4 B.I. p. 3.

Uberaba/MG. 21 de janeiro de 1966. Alvo de homenagens hoje, o comandante do

. Uberaba/MG. 21 de março de 1966. Notas da Polícia Militar. p. 4.

. Uberaba/MG. 30 de novembro de 1967. O que vai pelo 4 B.I. p. 4.

MARTINS FILHO, João Roberto. Forças Armadas e política, 1945-1964: a ante-sala do golpe. In: FERREIRA, Jorge; DELGADO, Lucilia de Almeida Neves (Org.). O Brasil

Republicano: tempo da experiência democrática: da democratização de 1945 ao golpe civil-militar de 1964. v. 3. 2. ed. Rio de Janeiro: Civilização Brasileira, p. 97-126, 2008.

MIGUEL, Luis Felipe. Segurança e desenvolvimento: peculiaridades da ideologia da segurança nacional no Brasil. Diálogos Latinoamericanos, Aarhus, n. 5, p. 40-56, 2002.

MIGUEL, Maria Elisabeth Blanck. Os arquivos e fontes como conhecimento da história das instituições escolares. In: NASCIMENTO, Maria Isabel Moura; SANDANO, Wilson; LOMBARDI, José Claudinei; SAVIANI, Dermeval (Org.). Instituições escolares no Brasil: conceito e reconstrução histórica. Campinas: Autores Associados; Sorocaba: Uniso; Ponta Grossa, UEPG, 2007.

MINAS GERAIS. Lei $n$. 489, de 10 de novembro de 1949. Cria o Ginásio Tiradentes no Departamento de Instrução da Polícia Militar. Disponível em:

<http://www.almg.gov.br/consulte/legislacao/completa/completa.html?tipo=LEl\&num=480\& comp $=\& a n o=1949>$. Acesso em: 19 set. 2015.

. Lei n. 4941, de 12 de setembro de 1968. Fixa normas para designação de estabelecimentos de ensino médio, mantidos pelo Estado. Disponível em: <http://www.almg.gov.br/consulte/legislacao/completa/completa.html?tipo=LEl\&num=4941 $\&$ comp $=\& a n o=1968 \& a b a=j s \_$textoOriginal $>$. Acesso em: 09 nov. 2016.

MINISTÉRIO DA EDUCAÇÃO E CULTURA. Ato n. 15/64, de 16 de abril de 1964. Inspetoria Seccional do Ensino Secundário de Uberaba. Uberaba, 16 de abril de 1964. (Arquivo do CTPM-Uberaba).

PMMG. 4ํㅡㄹ Batalhão de Infantaria. Circular n. 2, de 26 de maio de 1967. Uberaba, 26 de maio de 1967. (Arquivo do 4ํㅡㄹathão da PMMG).

. Nota do Gabinete, de 21 de março de 1966. Uberaba, 21 de março de 1966. (Arquivo do 4을 Batalhão da PMMG).

. Ofício n. 624, de 8 de fevereiro de 1966. Uberaba, 4 de março de 1966. (Arquivo do $4^{\circ}$ Batalhão da PMMG).

PMMG. Boletim do Comando Geral n. 01, de 4 de janeiro de 1965. Quartel GeneralAjudância Geral. Belo Horizonte, 4 de janeiro de 1965. (Arquivo do 4ํㅡㄹathão da PMMG).

. Boletim do Comando Geral n. 200, de 26 de outubro de 1964. Quartel GeneralAjudância Geral. Belo Horizonte, 26 de outubro de 1964. (Arquivo do 4ํㅡㄹatalnão da PMMG).

Edital n. 01/2014. Edital para inscrição, seleção e matrícula para o Colégio Tiradentes da Polícia Militar para o ano de 2015. Belo Horizonte, 9 de outubro de 2014. Disponível em:

<http://www.sistemas2pm.mg.gov.br/sorteioctpm/arquivos/edital_2015.pdf>. Acesso em: 19 set. 2015. 
Regimento Escolar do CTPM de Uberaba. Belo Horizonte, 07 de maio de 2008. (Arquivo do CTPM-Uberaba).

. Resolução n. 4.209, de 16 de abril de 2012. Aprova o Regulamento da Diretoria de Educação Escolar e Assistências Social (Deeas). Belo Horizonte, 16 de abril de 2012. Disponível em:

<https://www.policiamilitar.mg.gov.br/conteudoportal/uploadFCK/deeas/011220141029121 56.pdf>. Acesso em: 19 set. 2015.

SANFELICE, José Luís. História das instituições escolares. In: NASCIMENTO, Maria Isabel Moura; SANDANO, Wilson; LOMBARDI, José Claudinei; SAVIANI, Dermeval (Org.). Instituições escolares no Brasil: conceito e reconstrução histórica. Campinas: Autores Associados; Sorocaba: Uniso; Ponta Grossa, UEPG, 2007.

. História, instituições escolares e gestores educacionais. HISTEDBR, Campinas, $\mathrm{n}$. especial, pp. 20-27, ago. 2006.

STARLING, Heloísa Maria Murgel. Os Senhores das Gerais: os novos inconfidentes e o Golpe de 1964. Petrópolis: Vozes, 1985.

SILVA, Margarete Pereira da. O bispo de Juazeiro e a ditadura militar. In:

ZACHARIADHES, Grimaldo Carneiro (Org.). Ditadura militar na Bahia: novos olhares, novos objetos, novos horizontes. Salvador: EDUFBA, 2009.

SILVEIRA, Hely Araújo. Memórias do 4ํㅡㄹataão da PMMG. Uberaba: Arquivo Público de Uberaba, 1988.

VEIGA, Cynthia Greive. Cidadania e educação na trama da cidade: a construção de Belo Horizonte em fins do século XIX. Bragança: Ed. USF, 2002.

ANELISE MARTINELLI BORGES OLIVEIRA desenvolve a pesquisa de doutorado A leitura em um espaço de formação pautado nos valores militares: um estudo sobre o Colégio Tiradentes da Polícia Militar de Uberaba/MG no Programa de Pós-Graduação em Educação na Unesp - Marília/SP. É integrante, desde 2013, do Grupo de Estudos e Pesquisas sobre Linguagem, Ensino e Narrativa de Professores - Geplenp.

Endereço: Rua dos Andradas, 1147 - 38026-430 - Uberaba/MG - Brasil.

E-mail: anelisemartinelli@hotmail.com

RAQUEL LAZZARI LEITE BARBOSA é professora adjunta na Unesp - Assis/SP e professora orientadora no Programa de Pós-Graduação em Educação na Unesp - Marília/SP. Livredocente em Didática pela Unesp, Doutorado em Educação pela Unicamp e Mestrado em Educação pela PUC-SP. Coordena o Grupo de estudos e pesquisas sobre linguagem, ensino e narrativa de professores - Geplenp.

Endereço: Travessa Brasil, 505 - 19814-240 - Assis/SP - Brasil.

E-mail: raqueleite@uol.com.br

Recebido em 06 de novembro de 2015.

Aceito em 06 de novembro de 2016. 